\title{
ESTUDOS SOBRE A NUTRIÇÃO MINERAL DO SORGO GRANIFFERO. V. EFEITOS DAS DEFICIENCIAS DE MICRONUTRIENTES (NOTA) *
}

E. Malavolta, W.R. Accorsi \& G.D. Oliveira **

A.Q. da Silva, H. Silva, E.G. Queiroga \& J.C. Felício ***

F.D. Nogueira, P.A. Jaha, R.M. DelGuiudice \& V.L. Assis *** A. Cardoso, A.C. Ribeiro, A.K. Kato \& D.A. Cordeiro *** A.C.P. Aguirre, A.A. Caetano \& C.L.C. Garcia ***

\section{RESUMO}

\begin{abstract}
O sorgo granífero, var. TEY 101, foi cultivado em solução nutritiva na presença e ausência de microntutrientes. Foram obtidos sintomas de carência e foi feita a determinação dos teores desses elementos nas folhas.
\end{abstract}

\section{INTRODUÇÃO}

A diagnose visual de deficiências é dos métodos mais conhecidos e mais antigos para se determinar a falta de nutrientes no solo através das alterações produzidas na planta.

É às vezes complementada pela análise de folhas (ou de outros órgãos) o que, além deestabelecere de modo mais definitivo o diagnóstico visual permite avaliar o estado nutricional por comparação cam teores de elementos em plantas tidas como normais.

Uma revisão da literatura mostrou que não existe trabalho sistemático sobre deficiências de micronutrientes no sogro granífero.

* Entregue para publicação em 24-11-1977.

Com ajuda do BNDE (FUNTEC 293) e da FAPESP.

* Respectivamente: Dep. Química, CENA, Dep. de Botânica e Dep. de Química, E.S.A. "Luiz de Queiroz", USP.

*** Estudants pós graduados de Solos \& Nutrição de Plantas. 
Sabe-se que a espéce é particularmente sensível à deficiência de ferro (KRANTZ \& MELSTED, 1964). OHKI (1975) estudou em detalhe a nutrição do sorgo com respeito ao manganês. JACQUES et al., (1975) estudaram a absorção e a distribuição de diversos micronutrientes. Os sintomas de falta de zinco foram descritos de modo genérico por HOFFER \& KRANTZ (1961).

\section{MATERIAL E MÉTODOS}

O sorgo, var. TEY 101 foi cultivado em solução nutritiva de HOAGLAND \& ARNON (1950) número 1 completa e com deficiência de micronutrientes, usando-se água desmineralizada. Inclui-se um tratamento suplementar com dose excessiva de manganês (20 x a usual).

O ensaio foi repetido tendo havido pequenas variações nos detalhes experimentais numa e noutro vez.

As plantas receberam aeração contínua na solução nutritiva.

A colheita se fez quando os sintomas se mostravam mais evidentes.

A análise mineral foi feita por métodos convencionais: B - curcumina; $\mathrm{Cu}, \mathrm{Fe}, \mathrm{Mn}$ e $\mathrm{Zn}$ - espectrofotometria de absorção atômica; Mo - tiocionato.

\section{RESULTADOS E DISCUSSÃO}

\section{Sintomas de deficiência}

Cerca de 2 semanas depois de iniciado o tratamento, omissão, eram evidentes os sintomas de falta de boro: estrias esbranquiçadas e longitudinais nas folhas mais novas; tais estrias com o tempo, se mostravam translúcidas; redução do porte devido ao encurtamento dos internódios, as folhas parecendo se inserir $\mathrm{n}$ o mesmo nó.

As plantas sem cobre mostraram 15 dias depois do transplante clorose internerval concentrada na parte superior das folhas mais velhas, progredindo depois para a base; a expansão da lâmina era limitada nas regiões cloróticas o que provocava a constrição daquela; as folhas afetadas se encurvaram para baixo pendendo do colmo - tal sintoma, entretanto, tendia a desaparecer.

A carência de ferro se fez sentir menos de uma semana depois de omitido o elemento na solução nutritiva: clorose internerval das folhas mais novas, caminhando da base para o ápice; em seguida apareceram manchas pardas; com o tempo as folhas se tornaram esbranquiçadas e a clorose atingiu também as mais velhas; o crescimento foi reduzido. 
Menos de 2 semanas depois do transplante as folhas mais novas das plantas desprovidas de manganês na solução mostraram clorose internervacl que progredia da base do limbo para a parte superior; as nervuras e estreita faixa de tecido ao longo das mesmas permaneciam verdes.

Os sintomas observados no caso da omissão de molibdênio mostraram-se atípicos estando sujeitos a confirmação posterior: clorose nas folhas mais velhas progredindo da ponta para a base; faixas amareladas entre as nervuras e depois manchas pequenas e avermelhadas dispostas no sentido longitudinal as quais com o tempo, coalesciam; enrolamento das folhas afetadas.

A carência de zinco causou encurtamento de internódios e diminuição no comprimento do limbo; não houve perfilhamento ou ocorreu atrofiamento dos perfilhos emitidos; as folhas afetadas mostravam estrias amareladas internervais e necrose marginal.

A toxidez de manganês se acentuou um mês e meio depois de iniciado o tratamento: clorose internerval em todas as folhas, havendo, porém, maior intensidade nas mais novas em que a descoloração caminhou da base para a ponta; com a intensificação do sintoma as faixas amarelas internervais se expandiam e coalesciam; nas folhas mais velhas a clorose internerval era menos acentuada; as pontas com frequência se mostravam necrosadas.

\section{Matéria seca}

Os dados de produção de matéria seca dos dois experimentos aparecem na Tabela 1 . Verifica-se que o crescimento assim medido foi influenciado pelos tratamentos na seguinte ordem decrescente:

$-\mathrm{Fe}>-\mathrm{Zn}>-\mathrm{Mn}>-\mathrm{B}>-\mathrm{Mo}>-\mathrm{Cu}$; em um trabalho semelhante, LOCKMAN (1972) obteve o seguinte: - Fe, - Mn, $-\mathrm{Zn},-\mathrm{Cu}$ e $-\mathrm{B}$.

TABELA 1 - Produção de matéria seca

\begin{tabular}{lcccc}
\hline \multicolumn{5}{c}{ Matéria seca $(\mathrm{g})$} \\
I ratamento & $10^{\circ}$ expto. & $20^{\circ}$ expto. & Média & $\%$ \\
\hline Completo & 160,0 & 58,6 & 109,3 & 100 \\
$-\mathrm{B}$ & 123,2 & 18,9 & 71,0 & 65 \\
$-\mathrm{Cu}$ & 122,1 & 49,8 & 85,9 & 78 \\
$-\mathrm{Fe}$ & 45,2 & 0,7 & 45,9 & 42 \\
$-\mathrm{Mn}$ & 113,8 & 16,8 & 65,3 & 59 \\
$-\mathrm{Mo}$ & 105,7 & 40,9 & 73,3 & 67 \\
$-\mathrm{Zn}$ & 73,1 & 44,3 & 58,7 & 54 \\
Excesso Mn & - & 47,4 & - & - \\
\hline
\end{tabular}


TABELA 2 - Teores de micronutrientes encontrados nas folhas das plantas do tratamento completo $(*)$

\begin{tabular}{lcc}
\hline & $\begin{array}{c}p \text { p m } \\
\text { Elemento }\end{array}$ & \\
\hline $\mathrm{B}$ & $60^{\circ}$ experimento & $2 .^{\circ}$ experimento \\
$\mathrm{Cu}$ & 65 & $88-71$ \\
$\mathrm{Fe}$ & 555 & $17-16$ \\
$\mathrm{Mn}$ & 329 & $282-251$ \\
$\mathrm{Mo}$ & 3 & $160-69$ \\
$\mathrm{Zn}$ & 75 & $65-46$ \\
\hline
\end{tabular}

(*) $1 .^{\circ}$ número $=$ folhas inferiores, $2 .^{\circ}$ número $=$ folhas superiores

\section{Teor foliar de micronutrientes}

As tabelas 2 e 3 dão os teores de micronutrientes encontrados nas folhas das plantas do tratamento completo e daquelas com omissão desses elementos.

TABELA 3 - Teores de micronutrientes encontrados nas folhas de plantas deficientes

\begin{tabular}{|c|c|c|}
\hline Elemento & $\begin{array}{c}\mathrm{p} \mathrm{p} \mathrm{m} \\
\text { 1. }{ }^{\circ} \text { experimento }\end{array}$ & $20^{\circ}$ experimento \\
\hline B & 41 & $28-28$ \\
\hline $\mathrm{Cu}$ & - & $9-8$ \\
\hline $\mathrm{Fe}$ & 462 & 198 \\
\hline$\cdot M n$ & 23 & $35-22$ \\
\hline Mo & 0,5 & - \\
\hline$Z_{n}$ & 52 & $47-46$ \\
\hline Excesso $\mathrm{Mn}$ & - & $465-225$ \\
\hline
\end{tabular}

(*) $1 .^{\circ}$ número $=$ folhas inferiores, $2 .^{\circ}$ número $=$ folhas superiores

Comparando-se os dados obtidos nos dois experimentos nota-se aceitável concordância entre os mesmos, exceto no que se refere os teores de $\mathrm{Fe}$ e $\mathrm{Mn}$, muito maiores no primeiro. E que nesse ensaio as plantas estiveram durante um mês recebendo solução nutritiva contendo todos os macro e todos os micronutrientes: isto se refletiu no peso da matéria seca e no teor foliar de alguns elementos. Nos dois casos o alto conteúdo de ferro nas plantas deficientes chama atenção; deve-se recordar, entretanto, que o teor total desse elemento pode ser maior numa planta deficiente do que numa suprida com o mesmo. A relação $\mathrm{Fe} / \mathrm{Mn}$ é às vezes melhor indicador do estado nutricional com respeito ao 
ferro do que o teor desse micronutriente considerado isoladamente. De fato, no primeiro ensaio foram encontradas as seguintes relações $\mathrm{Fe} / \mathrm{Mn}$ :

$$
\begin{array}{ll}
\text { tratamento completo } & =1,7 \\
\text { tratamento }-\mathrm{Fe} & =0,6 ;
\end{array}
$$

vê-se, pois, que a relação variou muito mais que o conteúdo de ferro nas folhas. LOCKMAN (1972) analisando plantas inteiras no estágio inicial de desenvolvimento encontrou os seguintes teores no tratamento "completo"; B - $18 \mathrm{ppm}$; $\mathrm{Cu}-3$; Fe - 110, $\mathrm{Mn}-51$ e $\mathrm{Zn}-22$; quando havia omissão do elemento os níveis desciam para: $\mathrm{B}-3, \mathrm{Cu}$ - 3, $\mathrm{Fe}-90, \mathrm{Mn}-8, \mathrm{Zn}-6$. As diferenças encontradas entre os dados podem ser explicados tendo em conta fatores diversos tais como: variedade, condições experimentais, época de amostragem e órgãos analisados.

\section{CONCLUSÕES}

Os experimentos conduzidos permitem concluir que:

a) a deficiência de micronutrientes limita o crescimento do sorgo, particularmente a de ferro;

b) o excesso de $\mathrm{Mn}$ parece ser menos prejudicial que a sua falta, nas condições do ensaio;

c) os sintomas obtidos concordam em linhas gerais, com os descritos para a espécie eoutras gramíneas;

d) a variação no conteúdo de micronutrientes na folha quando o mesmo é omitido da solução é suficientemente grande para que os dados sirvam no diagnóstico do estado nutricional da variedade.

\section{SUMMARY}

STUDIES ON THE MINERAL NUTRITION OF GRAIN SORGHUM. V. EFFECTS OF DEFICIENCIES OF MICRONUTRIEN'TS

Grain sorghum var. TEY-101 was grown in nutrient solution in the presence and in the absence of micronutrients. Symptoms of deficieny of all micronutrients were obtained. Growth, as measured by dry matter production was affected by the treatments in the folowing decreasing, order: minus $\mathrm{Fe}$, minus $\mathrm{Zn}$, minus $\mathrm{Mn}$, minus $\mathrm{B}$, minus Mo and minus $\mathrm{Cu}$. An additional treatment in which excess $\mathrm{Mn}$ was used revealed a relative tolerance of the varicty to high levels of this element. The results of chemical analyses of the leaves suggest that the following contents (in $\mathrm{ppm}$ ) of micronutrients are associated with the respective deficiencies: $\mathrm{B}-20$ to $40, \mathrm{Cu}-8$ to $10, \mathrm{Fe}-198, \mathrm{Mn}-32$ to 35 , $\mathrm{Mo}-0.5, \mathrm{Zn}-46$ to 52 ; in the case of $\mathrm{Fe}$ the $\mathrm{Fe} / \mathrm{Mn}$ relationship seems to give a better indication of the nutritional status than the content of the element per se, being igual to 1.7 in the healthy plants, and 0.6 in the iron deficient ones. 


\section{LITERATURA CITADA}

HOAGLAND, D.R. \& D.I. ARNON. 1950. The water culture methor for growing plants without soil. Calif. Agr. Exp. Sta. Circ. 347.

HOFFER, G.N. \& B.N. KRANTZ. 1951. Deficiency symptoms of corn and small grains. Em: Hunger signs in crops. Ed. por F.E. Bear, David McKay, Nova Iorque.

JACQUES, G.L., R.L. VANDERLIP \& R. ELLIS JR. 1975. Growth and nutrient accumulation and distribution in grain sorghum. II $\mathrm{Zn}, \mathrm{Cu}, \mathrm{Fe}$ and $\mathrm{Mn}$ uptake and distribution. Agron. J. 67: 611-616.

KRATZ, B.A. \& S.W. MELSTED. 1964. Nutrient dieficiencias in corn, sorghum and small grains. Em: Hunger Signs in Crops. Edit. por H.B. Sprague. David Mc Kay Co., Nova Iorque.

LOCKMAN, R.B. 1972. Mineral composition of grain sorghum plant samples. Par II: As affected by soil acidity, soil fertility, stage of growth variety, climate facors. Comum. Soil Sci. Plant Anal. 3(4): 283-292.

OHKI, K. 1975. Manganese supply, growh and micronutrient concentration in grain sorghum. Agr. J. 67(1):328-330. 